15. Версе, О. Художник Леонтий Озерников // Проза.ру : [сайт]. URL:https://proza.ru/2020/09/19/69 (дата обращения: 20.02.2021).

Mariia $V$. Zaitseva

Saint-Petersburg State Institute of Culture (Saint Petersburg, Russia) centermtp@mail.ru

\title{
INTEGRATION OF LITERARY HERITAGE INTO MEMORIAL SPACE OF A MUSEUM
}

\begin{abstract}
The article discloses opportunities of widened presentation of literary heritage in historical and artistic exhibitions in Russian literary and memorial museums that are considered by the author as an alternative for reconstruction of memorial space based on typical materials. In reliance on an idea of key role of visual means in social and cultural communication, the author claims that text representation in visual format through the use of the newest technologies of museum design helps to refine effectiveness of perception of conceptional block of museum exhibit by a visitor, its capabilities to draw people's attention. Research sums years-long experience of work of three Russian literary museums (Varlam Shalamov's House Museum (Vologda, Vologda Oblast), Vasily L. Pushkin's House Museum (Moscow), Nikolai Gogol' House - Memorial Museum and Research Library (Moscow)), that shows usefulness of synthesis of memorial component of museum activities and spatial and figurative approach to presentation of literary heritage in museum space.

Key words: literary heritage, literary-memorial museum, design of museum expositions, Varlam Shalamov's House Museum, Vasily L. Pushkin's House Museum, Nikolai Gogol' House - Memorial Museum and Research Library, text visualization, a memorial exposition, a museum installation.
\end{abstract}

УДК [394.3:793.3] $(=512.1)$

DOI: $10.32340 / 2414-9101-2021-1-21-27$

И. Л. Мусухранов

Алтайский государственный институт культуры (Барнаул, Россия) eni4ka_mail.ru

\section{СВЯЗЬ АЛТАЙСКОЙ НАРОДНОЙ ИГРЫ И ТРАДИЦИОННОЙ ХОРЕОГРАФИИ АЛТАЙЦЕВ: ОПЫТ ПОСТАНОВКИ ПРОБЛЕМЫ}

Аннотация. Рассмотрена связь народной танцевально-пластической культуры алтайцев с некоторыми символическими и художественными образами, сюжетными мотивами празднично-обрядового комплекса и ритуальных народных игр коренного тюркского этноса Алтая. По мнению автора, хореографическое мышление алтайцев (в части драматургии, образного ряда, ритмики, структуры танца) сформировано под определяющим влиянием народной культуры, традиционных культов. Подчеркивается необходимость дальнейшего научного изучения историко-этнографического материала, характеризующего традиционную культуру алтайцев, в контексте приближения совре- 
менного народно-сценического танца к оригинальным образцам хореографического искусства алтайского этноса.

Ключевые слова: алтайцы, мифология алтайчев, народный алтайский танеи, традищионная хореография народов Алтая, народные игры, подвижные игры, архетипические образы, игровые соревнования.

Понятие «игры» многообразно и трудно поддается четкому определению. «Игра» в научном осмыслении это феномен и психологический и социальный. В практике исполнительских искусств игра - это основа творчества и неиссякаемый источник вдохновения. Народные игры служат базой для воплощения традиционного искусства, через игру можно полновесно воссоздать способ мышления и этнические традиции. Игры народные и традиционные включают в себя как различные забавы, так и виды спорта. Принцип состязательности имеет игровую развлекательную основу. Игра обязательно включает в себя элементы народной театрализации, масочности, своеобразного цирка. При воссоздании образцов народной хореографии, исконного танцевального языка необходимо учитывать и использовать такой богатый материал синкретического сплава искусств, какой дает нам традиционная народная игра. Ведь в ней неразделимы танец, музыка, песня, основы декоративно-прикладного искусства, и. что особенно важно, в игре все традиционные проявления видов народного искусства тесно, онтологически связаны с системой верований и религиозных представлений. Для полноценной работы в области постановок, связанных с традиционной танцевальной культурой народов Алтая необходимо разбираться в празднично-обрядовом компоненте этих этносов. Мы рассмотрим некоторые особенности традиционных игр народов Алтая, которые могут быть полезны в работе хореографа.

В алтайском языке «игра», «игры» обозначаются словом «ойын». У алтайцев основное ядро игр составляют игры, связанные со скотоводческим бытом. Кочевой народ не может создавать большие памятники материальной культуры, историческая культурная память скорее бытует в традиционных обрядах, традиционных видах искусства. Иными словами, в условиях отсутствия определенного географически локуса, артефакты культуры можно определять как «квазилокальные». При изучении культуры алтайцев, при анализе их традиционной хореографии, можно выделить то обстоятельство, что любое празднество годового цикла практически всегда состояло из двух обязательных частей: ритуальной, и развлекательной (играми, забавами, состязаниями). В рамках данной статье мы рассмотрим именно развлекательную, игровую часть праздничнообрядового действия, игру.

Формоопределяющим компонентом любой игры являются категории времени и пространства. По временному признаку игры можно разделить на три части:

1) круглогодичные игры, которые могут возникать независимо от времени года;

2) сезонные игры, связанные с конкретным временем года;

3) ритуальные игры, связанные с определёнными календарными праздниками и семейными обрядами (например, свадебными).

Конечно, предлагаемая классификация не является исчерпывающей. Народные алтайские игры дифференцируются, к примеру, и по половозрастному и по гендерному признаку. «По гендерному признаку игры делятся на мужские, женские и смешанные. 
По возрастному критерию выделяется детские, молодёжные, игры людей среднего и старшего возраста, и такие, в какие можно играть в любом возрасте» [1, с. 57].

Для современного хореографа особую значимость приобретают именно ритуальные игры. Именно в них скрупулёзно воссоздаются, реанимируются те элементы традиционной культуры, которые могут основой для хореографического выражения духовной жизни этноса. Представление о тесной связи между сакральным миром человека, магией, гаданием и игрой высказано в работах этнографа Леви-Брюля, и его последователей [2]. В качестве примера можно привести традиционную алтайскую игру: дети становятся в круг и передают друг другу лучину с огнём. У кого в руках гаснет огонь, тот выбывает из игры. В таком, на первый взгляд, примитивном действии мы видим отголоски мифологических представлений о божественной природе первородного огня, и, одновременно с этим наблюдаем элемент гадания, проверки удачливости и благосклонности судьбы. Из рук в руки передаётся не только вполне материальная горящая лучина, но передается символический огонь. Детская игра становится воплощением бесчисленного множества завещателей традиций, сказителей, мифографов. Вся мифологическая схема народа обретает действительный онтологический статус на время игры, то есть «Ноmo ludens» становится на небольшом отрезке времени демиургом. Это не просто игра, это - «символ жизни». Казалось бы, все это не соотносится с искусством хореографии, но, на наш взгляд, в танце воплощаются пластически те же элементы духовной жизни народа, что и в игре, и их изучение необходимо в работе современного хореографа, работающего в сфере народной танцевальной культуры.

Игры и состязания широко представлены в фольклорных памятниках, они неразрывно связаны с историей каждого конкретного народа. Тема состязаний актуальна почти во всех жанрах фольклора. В алтайских мифах о сотворении земли и животного мира говорится о состязании двух демиургов - Ульгеня и Эрлика. Они оба создавали землю, животных и человека. Сотворение мира, по верованиям алтайцев, представляет своеобразный конфликт-состязание двух равных по силе братьев. Они пребывают в вечном споре и соревновании. То есть в народных играх состязательный элемент имеет сакральную природу. В традиционной хореографии алтайцев также часто наблюдается своеобразное состязание на сцене в силе, ловкости, исполнении сложных акробатических элементов. «В другом мифе упоминается состязание двух великих рек Алтая Бии и Катуни. У алтайцев до сих пор бытуют предания о битвах священных гор. В преданиях о названиях года двенадцатилетнего календаря рассказывается состязании мыши и верблюда» [3, с. 112]. Все это подтверждает тот факт, что игры и состязания составляют своего рода зримую космогонию в мировоззрении алтайцев.

Анализ героических сказаний показывает, что в большинстве случаев состязания проходят по скачкам, меткой стрельбе, борьбе. Это не удивительно. «Именно эти виды состязаний были наиболее распространены в среде алтайцев. В настоящее время скачки и борьба «куреш» занимают значительное место в спортивных соревнованиях на национальном празднике «Эл ойьıн»» [4, с. 23].

Свадебная народная обрядность - это, практически всегда, независимо от этнической принадлежности, «театрализованное» мероприятие, в нем обряды и игры призваны воссоздавать историческую реальность в наиболее полной и доступной конкретике. Показательным в этом отношении нам кажется один из алтайских свадебных обрядов «бееле айгыр oйыны» (игра кобылицы и жеребца). О составе участников игры современные информанты сообщают по-разному. По нашим сведениям, в нем участвуют 
четыре человека: трое мужчин и женщина. Сама игра выглядит следующим образом: вокруг горящего очага бегает женщина, смазывая маслом или жиром нижний круг аила, за ней двигаются мужчины, изображающие жеребцов, они подражают конскому ржанию. Обряд посвящен плодородию и имеет, несомненно, яркую эротическую подоплеку. Подобное противопоставление «женского» и «мужского» в свадебной обрядности имеет большое значение при анализе традиционной хореографической культуры, которая апеллирует к языческому мировоззрению и его представлению о плодородии. «По другим сообщениям, в этом обряде участвовали трое: двое мужчин и женщина. Действующие лица обегали очаг три раза. Был и иной вариант: вокруг очага бегала одна женщина - сноха жениха, а жеребца изображал племянник жениха. Кобылиц могли изображать женщины, заплетавшие косы невесте. Жеребцов изображали племянник и брат жениха. Жеребцов и кобылиц могли изображать по два: две женщины - кобылиц и двое мужчин - жеребцов» [5, с. 26]. Со временем сакральный смысл призывания плодородия уступил в этой игре развлекательной гедонистической функции, но вне зависимости от восприятия действия участниками и окружающими, изначальная обрядовая компонента не устранена, что подтверждается обязательностью этой подвижной игры на современных традиционных свадьбах. Описанная нами игра относится к разряду подвижных игр, которые следует рассматривать как «осмысленную деятельность, направленную на достижение конкретных двигательных задач в быстроменяющихся условиях. В ней появляется творческая инициатива играющего, выражающаяся в разнообразии действий согласованная с коллективными действиями» [6, с. 12]. Таким образом, игра, связанная с движением, имеет в себе обязательный кинематический элемент, движения играющих запрограммированы самими условиями игры, которые, в свою очередь связаны с народными традициями и представлениями об устройстве мира. Хореография и подвижная игра, состязание, имеют общую природу - народное сознание и память, выраженные в телесном движении. Эта связь четко прослеживается на примерах исконной хореографии алтайцев. Более подробно примеры именно хореографические приведены автором в монографии «Мифоритуальная основа традиционного искусства на территории современного Горного Алтая» [3]

Механизмом трансляции традиций из поколения в поколение является обычай. Традиции в бытовом поведении, предписания во взаимоотношениях у алтайцев ярко проявляются в отношении детских игр. Сами правила этих действий имеют «обережную» основу, играющие не могут самовольно менять условия, и сам факт возникновения игровой ситуации обычно связывается с мифологическими представлениями. То есть детские традиционные игры приветствуются именно в силу своей «традиционности», связи с историческим народным временем и народной культурой. Например, когда в аиле начинается какая-то традиционная игра, присутствующим, не участвующим в игре, не рекомендуется слишком громко кричать или смеяться. Нами был записаны «охранительные» слова, если играющий случайно наступит на порог во время игры: «на золотую дверь», «на серебряные ворота», «на бронзовый порог». Этот пример показывает с одной стороны, какое значение имеет аил (юрта) (не только жилище, но микромир кочевника, все события в котором оказывают влияние на макромир), но и какое значение имеет игровой элемент, ведь даже в детской игре проявляется сакральная связь с миров богов и предков.

В играх, как и в традиционной хореографической культуре очевидно наличие архаических образов традиционного мышления, имеющих имена и совершенно определен- 
ные характеристики. Примером служит «кокымай»- персонаж-антагонист, сходный по характеристикам со славянской «бабой Ягой», то есть существа, имеющего страшный внешний облик. Близкими по значению являются «когок» или «коох». «Ими пугают детей, то есть они персонифицируют первоначальное зло, с которым дети должны быть знакомы с как можно более раннего возраста, чтобы уметь отличать добро от зла. Персонажи, подобные «кокымаю» появляются в некоторых играх («Аксак эмеен»)» [8, с. 33]. Нам представляется важной связь традиционного «благопожелания» и позы коленопреклонения в культуре алтайцев.

«Алкыш сос» (благопожелание) - раздел алтайского устного поэтического наследия - «представляет собой многофункциональное явление богатство жанровой разновидности. «Алкыш сос» означает благословение, добропожелание, заклинание, моление, славословие» [8].

Благопожелание - это выражение любви к природе Алтая, к Алтаю как родине, к уважаемым людям, в особых случаях. В них выражается и просьба о помощи.

Откуда появились благопожелания? В легенде говорится, что хозяйка источника Аржан-Суу лечила охотника, который сломал ногу, и рассказывала ему о лечении на целебных источниках, восхваляя и благодаря их. С тех пор охотник стал всем рассказывать об этом. А также духи поведали людям о благопожеланиях. С тех пор человек стал выражать благопожелания природе.

Почитая природу, считая себя составной частью ее, алтайцы относятся к ней очень бережно: не позволяют рубить деревья без надобности, рвать цветы, ломать ветки деревьев. Коренные жители говорят, что Алтай надо уважать как отца, любить как мать, надо одаривать природу опрыскиванием места пребыванием молоком и повязыванием белой ленты (дьяалама). Природа создана для того, чтобы человек пользовался ее дарами, но злоупотреблять ее богатством нельзя, нужно в природе все брать в меру. Если люди нарушают закон равновесия природы, то она отомстит неудачей на охоте, болезнями, вымиранием целого рода.

Тех, кто не любит природу, окружающих сородичей, слишком жаден до богатства, употребляет алкоголь, не проявляет заботы о семье, детях, родителях и стариках, Алтай наказывает. Тогда говорят: «Алтай свирепеет», «Алтай обижается». Благопожелания по отношению к людям существуют и у русского народа, а благопожелания, связанные с одухотворением природы, присущи не только алтайцам, но и другим тюркским народам. С этой устной традицией, на наш взгляд можно связать традицию коленопреклонения, характерную для алтайского поклона в хореографии. Эта поза прослеживается по древнетюркским материалам - коленопреклонение статуи поминального комплекса в честь Кагана Кюль-Тегина на реке Орхон (первая половина VIII в. н. э.) и сохраняется у алтайцев до настоящего времени.

У каждой возрастной категории существовала определённая поза сидения. Мужчины и женщины в знак уважения к окружающим должны сидеть коленопреклонённо (чёмчёйиn), левую ногу подогнув под себя, а правую согнув в колене. Только старейшие мужчины могли сидеть, держа ноги крест-накрест (табланыл).

Традиционная поза коленопреклонения, имевшая место в будни и в праздники, отвечала этическим нормам алтайского общества. Мужчины носили в правом голенище обуви необходимые вещи, например кисет или нож, а присев на левое колено, могли удобно достать его. Обычай сидеть коленопреклонённо имел не столько практические, сколько символические функции. В представлении народа коленопреклонённая поза 
имела выраженный позитивный смысл и связывалась такими понятиями, как степенность, доля, удача. У алтайцев коленопреклонение - необходимая часть обрядовых действий. Например, присев коленопреклонённо, можно было совершать ритуал кропления огня, что отчётливо прослеживается в свадебной обрядности.

В коленопреклонении алтайцев имеет место важный элемент - подношение угощения, где прослеживается положение «правое-левое» - правой рукой придерживая локоть. Культурные установки поддерживают праворукость. В представлении алтайского народа правое ассоциируется с правдой, «правильным», в тоже время как левое - с ложью, неправдой, неправильным. Правая рука осмысливается как «рука благодати» и ей отдаётся предпочтение в совершении ритуальных действий. С коленопреклонением, кроме жеста правой руки, сочетался другой - ритуальный поклон головы. Голова с древнейших времён считалась как наиболее важная часть и человека, и животных. Таким образом, в традиционной культуре алтайского народа коленопреклонение является основной бытовой и обрядовой позой и выражает степенность, спокойствие национального характера, также почитание окружающих.

Наличествование общих компонентов, символов, персонажей в традиционной игре и хореографии ведет к поиску синкретизма функционирования культуры и традиционного искусства в историческом аспекте. Не понимая мировоззренческой основы народного искусства, его мифоритуальной составляющей, невозможно говорить об осознании его основ и предполагать его развитие в будущем. Все исследования, экспедиционные записи должны находить свое выражение в практической деятельности деятелей искусства. Можно увидеть, что за «традиционную хореографию» часто выдаются наборы движений, внешне схожих с истинно народными, но имеющими природу только профессионального исполнительского искусства. Это происходит от разрыва между научной деятельностью хореографов, этнографов, искусствоведов и ее практическим применением. С другой стороны все меньше хореографов применяют научные данные в своей работе. Ориентация на достижение коммерческого художественного результата приводит к элиминации из «народного» искусства истинно народных элементов. Важнейшим компонентом традиционного хореографического искусства, на наш взгляд, является его связь с коллективной памятью этноса, его традиционной мифологией и космогонией. Для успешного освоения принципов истинно «народной» хореографии необходимо совмещение процессов осмысления и воплощения в практической деятельности хореографа. Связь традиционного канона игр и традиционной хореографии у народов Алтая несомненна и требует как дальнейшего научного осмысления, так и своего сценического воплощения.

\section{Список литературы}

1. Торуше, Е. Г. Роль народных развлечений и устного творчества в воспитании молодежи алтайцев // Полевые исследования в Горном Алтае на современном этапе (археология, этнография) : сб. науч. тр. - Горно-Алтайск : РИО ГАГУ, 2009. - С. 56-63.

2. Леви-Брюль, Л. Сверхъестественное в первобытном мышлении. - Москва : Педагогика-Пресс, 2017. - 608 с.

3. Зуев, И. Н. Мифоритуальная основа традиционного искусства на территории современного Горного Алтая : моногр. / И. Н. Зуев, И. Л. Мусухранов. - Барнаул : Изд-во Алт. гос. ин-та культуры, 2020. - 157c.

4. Горохов, А. Краткое этнографическое описание бийских или алтайских калмыков // Слово об Алтае. - Кн. III, ч. I : Землеведение. Флора и фауна. Этнография. Религия. История. - Горно-Алтайск : [Алт. кн. изд-во], 2004. - С. 43-58. 
5. Торбоков, А. Алтай шатра. Правила и комбинации в шатре. - Горно-Алтайск : The first step, 2013. - $34 \mathrm{c}$.

6. Теория и история игры / [редкол. : В. М. Григорьев, С. В. Григорьев (отв. ред.) и др.]. - Вып. 1 : Памяти Е. А. Покровского. - Москва : ODU-International, 1995. - 108 с.

7. Сатлаев, Ф. А. Кумандинцы (историко-этнографический очерк XIX - первой четверти XX в.). - Горно-Алтайск : [Алт. кн. изд-во], 1974. - 200 с.

8. Краткий словарь этнографических и фольклорных понятий и терминов / сост. : В. П. Ойношев. - Горно-Алтайск : [...], 2011. - 90 с.

Igor L. Musukhranov

Altai State Institute of Culture (Barnaul, Russia) eni4ka@mail.ru

\title{
RELATION BETWEEN ALTAIANS' PEOPLE'S GAME AND ALTAIAN TRADITIONAL CHOREOGRAPHY: PROBLEM STATEMENT
}

\begin{abstract}
The paper considers a relation between dance and plastic culture of Altaians and some symbolic and artistic images, plot devices of feast and ritual complex and ritual people's games of the indigenous Turkic people of Altai. On the author's opinion, choreographic thinking of Altaians (in dramaturgy, imagery, rhythm, structure of dance) developed under the influence of people's culture, traditional cults. A need of further scientific examination of historical and ethnographic materials reveal traditional culture of Altaians in the context of approximation of today's version of folk stage dance to original examples of Altaian ethnos' choreographic art is stressed out.

Keywords: Altaians, Altaians' mythology, Altaian people's dance, traditional choreography of peoples of Altai, people's games, outdoor physical games, mythic images, a game, competitive games.
\end{abstract}

УДК 338.482.224:910.4-51(570.150+570.151)

DOI: 10.32340/2414-9101-2021-1-27-34

М. В. Рыгалова, кандидат исторических наук Алтайский государственный университет (Барнаул, Россия) mariya_rygalova@mail.ru

\section{ВКЛАД ИССЛЕДОВАТЕЛЕЙ В ИЗУЧЕНИЕ АЛТАЯ: К ВОПРОСУ ОБ АКТУАЛИЗАЦИИ НАСЛЕДИЯ}

\begin{abstract}
Исследование выполнено при финансовой поддержке Совета по грантам Президента Российской Федераџии, проект № МК-4173.2021.2 «По маршрутам исследователей и путешественников Алтая: актуализащия наследия средствами ГИС-технологий»
\end{abstract}

Аннотация. Рассмотрены общие вопросы интеграции краеведческого историкокультурного наследия в сферы внутреннего экскурсионно-познавательного, рекреационного туризма на Алтае. Охарактеризован образовательно-просветительный потенциал научной реконструкции и популяризации в среде потребителей туристических услуг крупных маршрутов отечественных и иностранных исследователей Алтая, путеше- 